\title{
BİYODİZEL YAN ÜRÜNÜ GLİSERİNİN ESTERLEŞME VE ASETİLASYONU İLE DEĞERLİ KİMYASALLARIN ỬRETİMİ
}

\author{
Emine Kaya EKİNCí ${ }^{1}$, Gamze GÜNDÜZ $Z^{2}$, Nuray OKTAR ${ }^{1}$ \\ ${ }^{1}$ Gazi Üniversitesi Mühendislik Fakültesi Kimya Mühendisliği Bölümü, Ankara \\ ${ }^{2}$ Bilecik Şeyh Edebali Üniversitesi, Kimya ve Süreç Müh. Bölümü,Gülümbe Kampüsü, 11210 Bilecik \\ eminekaya@gazi.edu.tr, gamze.gunduz@bilecik.edu.tr, nurayoktar@gazi.edu.tr
}

(Geliş/Received: 10.11.2014; Kabul/Accepted: 31.07.2015)

ÖZET

Çevreci bir yakıt olan biyodizel çeşitli avantajlarından ötürü dizel yakıta alternatif bir yakıttır. Bitkisel yağın metanol veya etanol ile transesterleşmesiyle biyodizel üretilmekte ve yan ürün olarak önemli miktarda gliserin oluşmaktadır. Gliserinin asetik asitle esterleşmesi biyodizel üretiminden kaynaklanan artan gliserinin değerlendirilmesi açısından alternatif bir çözüm teşkil eder. Yapılan çalışmada gliserinin asetik asitle esterleşme reaksiyonu Smopex-101 varlığında sıvı faz kesikli otoklav reaktörde incelenmiştir. Yapılan reaksiyon çalışmalarında oda sıcaklığında oldukça kısa sürede (25 dakika) \%100 gliserin dönüşümüne ulaşılmıştır. Reaksiyon sıcaklığı ve başlangıç reaktan molar oranlarının gliserin dönüşümü ve ürün seçiciliği açısından etkisi incelenmiştir. En yüksek diasetin (\%77) ve triasetin (\%23) seçiciliğine 363K'de ve gliserin/asetik asit;1/12 molar oranında ulaşılmıştır. Triasetin seçiciliğini artırmaya yönelik asetil klorür ile Smopex-101 varlığında asetilasyon reaksiyonu gerçekleştirimiştir. Oda sıcaklığında gerçekleştirilen çalışmalarda 1200 dakika sonunda \%60 triasetin seçiciliğine ulaşılmıştır.

Anahtar Kelimeler: Smopex-101, gliserin, esterleşme, asetilasyon

\section{PRODUCTION OF VALUABLE CHEMICALS VIA ESTERIFICATION AND ACETYLATION OF GLYCEROL, BY-PRODUCT OF BIODIESEL}

\begin{abstract}
Biodiesel is an alternative fuel to gasoline due to its environmental and economical benefits. Glycerol is the main by-product of the biodiesel production by transesterification of vegetable oil with methanol or ethanol. The esterification of glycerol with acetic acid can be a good choice for utilization of by-product glycerol. In this work esterification of glycerol with acetic acid was performed in liquid phase autoclave batch reactor in the presence of Smopex-101. Complete glycerol conversion was achieved in the reaction studies even at room temperatures. Effects of reaction temperatures and initial reactant molar ratios on the glycerol conversions and product selectivity were also investigated. The maximum diacetin (77\%) and triacetin (23\%) selectivities were achieved at $363 \mathrm{~K}$ and glycerol/acetic acid; 1/12 molar ratio. Acetylation reactions were performed with acetyl chloride in the presence of Smopex-101 in order to increase triacetin selectivity. $66 \%$ triacetin selectivity was achieved in acetylation reaction studies in a period of 1200 minutes at room temperature.
\end{abstract}

Keywords: Smopex-101, glycerol, esterification, acetylation

\section{GÍRİŞ (INTRODUCTION)}

Gliserin bitkisel yağın metanol veya etanol ile transesterleşmesiyle biyodizel üretiminde yan ürün olarak oluşur. Bilindiği üzere çevreci bir yakıt olan biyodizel çeşitli avantajlarından ötürü dizel yakıta alternatif bir yakıttır. Biyodizel kullanımı ve üretimi arttıkça gliserin üretimi artmakta ve fiyatı düşmektedir. Yaklaşık olarak transesterleşme ile her $90 \mathrm{~m}^{3}$ biyodizel üretiminde $10 \mathrm{~m}^{3}$ gliserin (gliserol) oluşmaktadır [1]. Gliserinin yapısında bulunan $\mathrm{OH}$ grupları esterleşme reaksiyonları bakımından elverişlidir. Gliserinin asetik asitle esterleşmesi biyodizel üretiminden kaynaklanan artan gliserinin 
<smiles>CC(=O)O</smiles>

Gliserin Asetik asit<smiles>C=CC(CO)C(CO)OC(C)=O</smiles>

Monoasetin<smiles>CC(=O)OC(CO)CO</smiles>

Monoasetin<smiles>CC(=O)OCC(CO)OC(C)=O</smiles>

Diasetin<smiles>C=C</smiles>

Asetik asit<smiles>CC(=O)OCC(CO)OC(C)=O</smiles>

$$
\text { Diasetin }
$$<smiles>CC(=O)OCC(COC(C)=O)OC(C)=O</smiles>

Triasetin

Şekil 1. Gliserinin asetik asitle esterleşme reaksiyonu (Esterification of glycerol with acetic acid)

değerlendirilmesi açısından alternatif bir çözüm teşkil eder. Oluşan ürünler monoasetilgliserid (monoasetin; MA), diasetilgliserid (diasetin; DA) ve triasetilgliserid (triasetin; TA)' dir (Şekil 1). Gliserinin asetik asitle esterleşme reaksiyonları birbirini takip eden seri reaksiyonlardan oluşmaktadır. Triasetin, triasetilat türevleri olarak bilinir ve kozmetikten yakıt katkısına kadar geniş bir uygulama alanına sahiptir. Monoasetin ve diasetin ise kriyojenide ve biyolojik olarak parçalanabilen polyester üretiminde hammadde olarak kullanılırlar [2]. Monoasetin ayrıca gıda ve ilaç sanayinde de kullanılmaktadır [3, 4]. Yakıt katkı maddesi olarak kullanılan triasetin yakıtın oktan sayısını arttırmaktadır [3].

Esterleşme reaksiyonları katalizörsüz olarak reaksiyonda kullanılan karboksilli asidin otoprotolizi ile gerçekleşmektedir. Ancak reaksiyon hızı oldukça yavaş olup, günlerce sonra bile denge dönüşümlerine ulaşılmamaktadır [5,6]. Bununla birlikte esterleşme reaksiyonları tersinir reaksiyonlar olup, heterojen veya homojen asit katalizörler eşliğinde gerçekleşebilmektedir. Homojen katalizörler olarak, $\mathrm{H}_{2} \mathrm{SO}_{4}, \mathrm{HCl}$, HF gibi mineral asitler kullanılmaktadır. Mineral asitlerin korozif özellikte olması, yan reaksiyonlara neden olması, reaksiyon karışımından kolaylıkla ayrılamaması bu sebeple reaksiyon sonunda nötralize edilmesinin gerekliliği gibi elverişsiz özelliklere sahiptir. Elde edilen ürünlerin saflaştırılmasında ek prosesler ve ek maliyetler getirir ki bu da ürün maliyetini arttırır [7,8]. Heterojen katalizörler, yüksek aktivite ve seçiciliğe sahip olması ayrica kolay ayrilabilir olması nedenleriyle son y1llarda oldukça rağbet görmektedir. Zeolitler, iyondeğiştirici reçineler, zirkonya, niobikasit ve asidik karakterli silika oksit katalizörler heterojen katalizörler olarak esterleşme reaksiyonlarında kullanılmaktadır [7-12]. 
Bir tür esterleşme reaksiyonu olan gliserinin asetik asitle tepkimesi sonucunda oluşan gliserin esterlerinin uygulama alanı çok olmasına rağmen bu konuda çok az sayıda çalışma vardır. Özellikle ürün seçicilikleri açısından yapılan araştırmalarda yakıt katkısı olarak kullanılabilen son ürün triasetine olan ilgi yoğundur. Ancak yapılan çalışmaların çoğunda reaksiyon sonucunda ürün karışımı elde edilmektedir [1, 13-15]. Oluşan ürünlerin kaynama noktalarının birbirilerine çok yakın olması ürün saflaştırma işlemlerini güçleştirmekte ve maliyeti arttırmaktadır. Liao ve arkadaşları iyon değiştirici reçine katalizörler (Amberlyst-15 ve Amberlyst-35) varlığında 105 ${ }^{\circ} \mathrm{C}$ 'de gliserinin asetik asitle esterleşmesi üzerine yaptıkları çalışmada, triasetinin seçiciliğini iki basamakta \%100'e getirebildiklerini belirtmişlerdir. Çalışmada gliserinin asetik asitle esterleşme reaksiyonunda dönüşümün \%100'e ulaşmasını takiben, triasetin seçiciliğini artırmak için aynı sicaklıkta $\left(105^{\circ} \mathrm{C}\right)$ asetilasyon reaksiyonu gerçekleştirilmiştir. Triasetin seçiciliği ortama eklenen asetik asit türevi olan asetik anhidritle ani bir artışla \%100 e ulaşmıştır [2].

Yapılan çalışmada öncelikle Smopex-101 fiber bazlı katalizör varlığında gliserinin asetik asitle esterleşme reaksiyonu çalışılmış daha sonra tek ürün (triasetin) elde etmek üzere gliserin dönüşümü \% 100 ' e ulaştıktan sonra ortama asetil klorür ilave edilerek asetilasyon reaksiyonu gerçekleştirilmiştir. Asetil klorür, literatürdeki asetik anhidrit maddesine benzer şekilde triasetin seçiciliğini artırmak için asetilasyon ajanı olarak kullanılmıştır. Çalışmada kullanılan yeni nesil katalizör olan Smopex-101 literatürde farklı alkollerin esterleşme reaksiyonlarında kullanılmış ve iyon değiştirici reçine katalizörler olan Amberlyst gruplarından daha etkili oldukları belirtilmiştir. $[16,17]$.

\section{YÖNTEM (METHOD)}

Gliserinin asetik asit esterleşme reaksiyonu yeni nesil reçine katalizörlerinden olan fiber bazlı, polimerik yapıya sahip Smopex-101 (Alfa- Aesar) katalizörü varlığında gerçekleştirilmiştir. Reaksiyon çalışmaları sıcaklık ve basınç kontrollü paslanmaz çelik kesikli otoklav reaktörde (Berghof) gerçekleștirilmiștir Yapılan reaksiyon çalışmalarında öncelikle otoklav reaktör istenilen reaksiyonun gerçekleştirileceği uygun sıcaklığa getirilir. Daha önce belirlenen başlangıç reaktan molar oranlarında hazırlanan reaktan karışımı (toplam reaksiyon çözelti hacmi 50 $\mathrm{ml}$ ) bir kapta istenilen reaksiyon sicaklığına getirilerek, reaksiyon sıcaklığındaki reaktöre transfer edilir ve katalizör ilave edilerek otoklav reaktör kapatılır. Reaksiyonlar otojenik basınçta, sıvı fazda ve manyetik karıştırıcı vasıtasıyla ayarlanan karıştırma hızında gerçekleştirilir. Çalışmada reaktan ve ürün analizleri split/splitless enjeksiyon bloğu donanımlı gaz kromotografi cihazıyla (Agilent 6890 GC) yapılmıştır. Çalışmaya uygun olarak alev iyonlaşma dedektörü (FID) ve HP-Innowax kapiler kolon kullanılmıştır. Gliserinin asetik asitle esterleşme reaksiyon çalışmalarında, reaksiyon sıcaklığının ve başlangıç reaktan molar oranlarının gliserin dönüşümüne ve ürün seçiciliğine etkisi incelenmiştir. Reaksiyon sıcaklığının gliserin dönüşümü ve ürün seçiciliklerine etkisini incelemek için Smopex-101 katalizörünün maksimum dayanım sıcaklığı (363 K) göz önünde bulundurularak, 343-363 K sicaklık değerleri arasında reaksiyon çalışmaları gerçekleştirilmiştir. Gliserin/Asetik Asit (G/AA) başlangıç molar oranı: 6/1 ve kütle transfer direncini bertaraf etmek için karıştırma hızı 1000 rpm' de sabit tutulmuştur. Yapılan tüm deneylerde 0,5 g katalizör (yaklaşık gliserin miktarının \%5'i, toplam çözelti miktarının ise \%0.93) miktarında çalışılmıştır. Başlangıç reaktan molar oranlarının gliserin dönüşümüne ve ürün seçiciliğine etkisini incelemek için karıştırma hızı ve katalizör miktarı sabit tutularak $363 \mathrm{~K}$ reaksiyon sicaklığında $\mathrm{G} / \mathrm{A} ; 1 / 6,1 / 9$ ve $1 / 16$ molar oranlarında deneysel çalışmalar gerçekleştirilmiştir.

Asetilasyon çalışmalarında öncelikle Smopex-101 varlığında gliserinin asetik asit esterleşme reaksiyonu gerçekleştirilmiş, gliserin dönüşümü \% $\% 100$ ' e ulaştıktan sonra ortama asetil klorür ilave edilmiştir. Asetil klorürün otoklav reaktörde korozyona sebebiyet vermesinden dolayı, asetilasyon reaksiyon deneyleri cam reaktörde gerçekleştirilmiştir. Cam reaktör reaksiyondaki muhtemel buharlaşma kayıplarının önüne geçebilmek amacıyla geri soğutucuya bağlanmıştır. Asetilasyon reaksiyon çalışmaları oda sıcaklığında (298 K) gliserin/ asetil klorür / asetik asit; 1/1/6 molar oranlarında 0,5 g katalizör miktarında ve 1000 rpm karıştırma hızında gerçekleştirilmiştir.

\section{BULGULAR VE TARTIŞMA (RESULTS AND DISCUSSION)}

Sunulan çalışmada gliserinin asetik asitle esterleşme reaksiyonu fiber katalizör Smopex-101 varlığında sıv1 fazda, otojen basınçta incelenmiştir. Öncelikle oda sıcaklığında (298 K) G/AA; 1/6 başlangıç reaktan molar oranında gerçekleştirilen reaksiyon çalışmasında ilk 25 dakikada dahi tam gliserin dönüşümüne (\%100) ulaşıldığ1 görülmüştür. Literatürde Amberlyst gruplarıyla yapılan çalışmalarda (A-15, A-35) daha yüksek sicaklıkta $(378 \mathrm{~K})$ gerçekleştirilen reaksiyon çalışmalarında ancak 3-5 saatte gliserin dönüşümü \%100' e ulaşabilmektedir [2]. Smopex-101, fiber polimer destekli sülfonik asit içerikli ipliksi yapıya sahip polistren bazlı bir katalizördür Esterleşme reaksiyonlarında oldukça sık kullanılan Amberlyst katalizörler ise stiren monomerinin divinilbenzen ile çarpraz bağlanması sonucu elde edilen asidik iyon değiştirici reçinelerdir. Her iki katalizörde de sülfonik $\left(-\mathrm{SO}_{3}\right)$ grupları yapıya asidik özellik katmaktadır. 


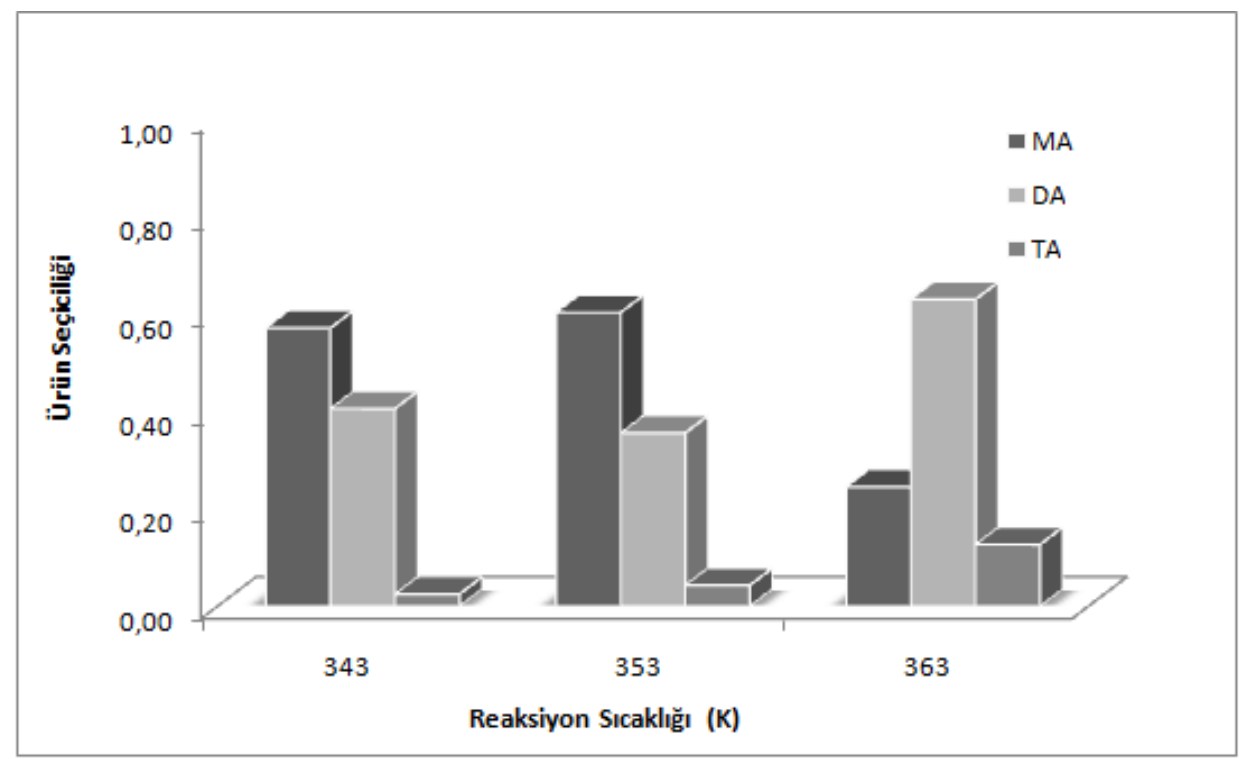

Şekil 2 Reaksiyon sıcaklığının ürün seçiciliğine etkisi, katalizör miktarı; 0,5 g, G/AA molar oranı; 6/1, karıştırma hızı; $1000 \mathrm{rpm}$, Süre; 285. dakika (Effect of temperature on the product selectivities, amount of catalyst; 0.5g, G/AA molar ratio; 6/1, Stirring rate; $1000 \mathrm{rpm}$, time; 285th minute)

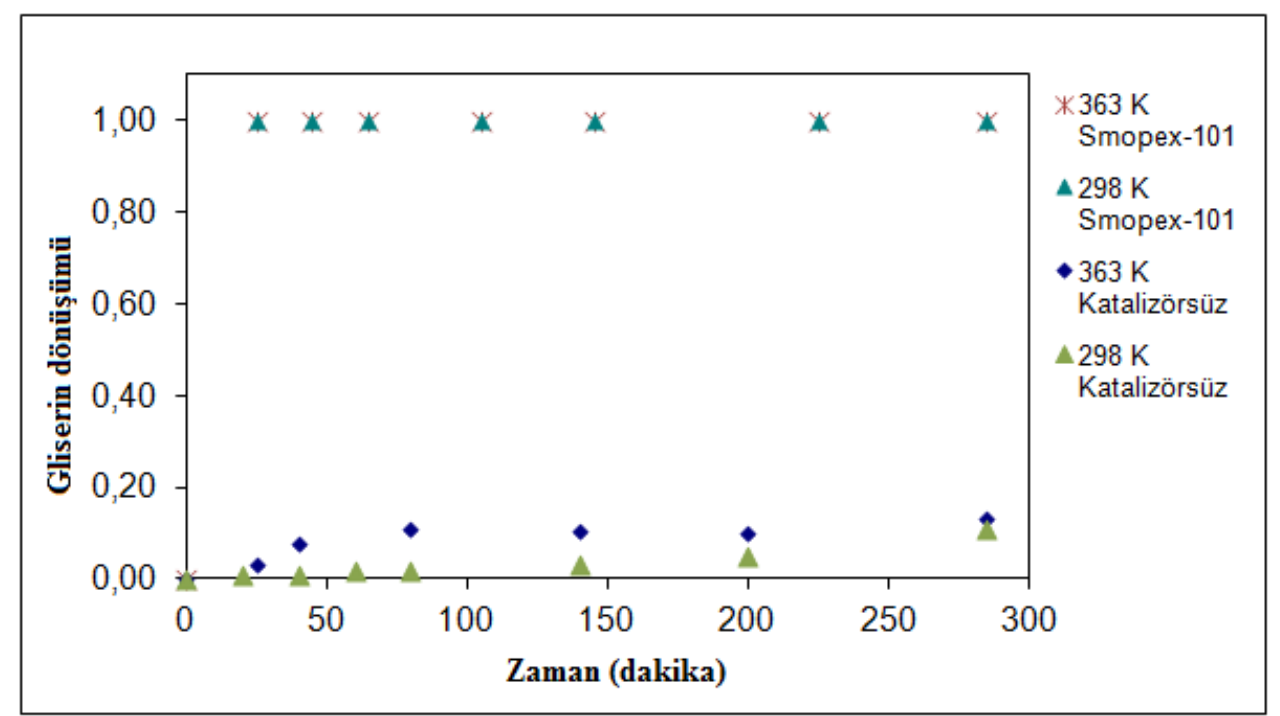

Şekil 3. Gliserinin asetik asitle esterleşme reaksiyonu gliserin dönüşüm değerleri, katalizör miktarı; $0,5 \mathrm{~g}$ G/AA molar oranı; 6/1, karıştırma hızı; $1000 \mathrm{rpm}$ (Esterification of glycerol with acetic acid, conversion datas, amount of catalyst; $0.5 \mathrm{~g}, \mathrm{G} / \mathrm{AA}$ molar ratio; $6 / 1$, stirring rate; $1000 \mathrm{rpm})$

Smopex-101'in iyon değiştirme kapasitesi 3,4 mmol $\mathrm{H}^{+} / \mathrm{g}$ kuru katalizör, Amberlyst-15'in 4,7 mmol H$/ \mathrm{g}$ kuru katalizördür [18]. Bununla birlikte Smopex101'in çarpraz bağlanma derecesi Amberlyst-15'den daha düşüktür. Polimerik katalizörlerde çarpraz bağlanma derecesi azaldıkça katalizörün polar ortamlardaki şişme kapasiteleri artmaktadır, dolayısıyla reaktanların aktif bölgelere ulaşması kolaylaşır [16]. Farklı araştırmacıların, Smopex-101 ve reçine katalizör Ambelyst-15 ile farklı asit ve farklı alkol çeşitleriyle gerçekleştirmiş oldukları esterleşme reaksiyonları sonucunda sülfonik asit destekli fiber bazlı Smopex-101 katalizörünün kimyasal olarak oldukça aktif olduğu görülmüştür [16-18].

\subsection{Reaksiyon Sıcaklığının Gliserin Dönüşümüne ve Ürün Seçiciliklerine Etkisi (Effects of Reaction Temperature on Glycerol Conversion and Product Selectivities)}

Smopex-101 varlığında gerçekleştirilen gliserinin asetik asitle esterleşme reaksiyonunda reaksiyon sıcaklığının gliserin dönüşümüne ve ürün seçiciliklerine etkisini görmek üzere $343 \mathrm{~K}, 353 \mathrm{~K}$ ve $363 \mathrm{~K}$ 'de reaksiyon çalışmaları gerçekleştirilmiștir. Yapılan çalışmalarda ilk 25 dakika gibi kısa bir sürede gliserin dönüşümü \%100'e ulaşmaktadır. Çalışmada ürün seçicilikleri açısından reaksiyon 285 dakika süresince incelenmiștir. Sekil 2'de farklı sıcaklıklarda gerçekleştirilen gliserin asetik asit 
reaksiyon çalışmalarına ait 285. dakika için ürün seçicilikleri verilmiştir. Reaksiyon sıcaklığının ürün seçiciliklerine etkisi incelendiğinde; sıcaklık arttıkça MA seçiciliği azalırken, sırasıyla DA ve TA seçiciliklerinin arttığı gözlenmiştir. $363 \mathrm{~K}$ reaksiyon sıcaklığında, 285 dakika sonunda DA seçiciliği \% 63 ve TA seçiciliği \% 14' e yükselmiştir.

Gliserinin asetik asitle esterleşme reaksiyonunda farklı reaksiyon sıcaklıklarının yanı sıra katalizörlü ve katalizörsüz ortamın gliserin dönüşümü ve ürün seçiciliklerine etkisini görmek amaciyla gerçekleştirilen deneysel çalışmalara ait zamana karşı gliserin dönüşümleri Şekil 3'de verilmiştir. 265 dakika sonunda katalizörsüz ortamda $298 \mathrm{~K}$ reaksiyon sıcaklığında \% 11 gliserin dönüşümü elde edilirken, 363 K'de gliserin dönüşümü \% 13'e yükselmiştir. Smopex-101 varlığında $298 \mathrm{~K}$ ve $363 \mathrm{~K}$ sicaklıklarında gerçekleştirilen reaksiyon çalışmalarında 25. dakika her iki reaksiyonda da \% 100 gliserin dönüşümüne ulaşılmıştır.
Tablo 1'de katalizörlü ve katalizörsüz ortamda gerçekleştirilen gliserinin asetik asitle esterleşme reaksiyonuna ait deneysel sonuçlar özetlenmiştir. 265 dakika sonunda elde edilen ürün seçiciliklerine bakıldığında oda sıcaklığında gerçekleştirilen çalışmalarda MA seçiciliğinin daha fazla olduğu dikkat çekmektedir. Ancak katalizörsüz reaksiyonun oldukça yavaş gerçekleştiği ve gliserin dönüşümü açısından reaksiyonun tamamlanmasının günler alacağı görülmektedir. MA açısından zengin ürün elde edilmek isteniyorsa Smopex-101 varlığında oda sıcaklığında yapılacak çalışmanın yeterli olduğu görülmüştür.

$\mathrm{Bu}$ şartlarda gerçekleştirilen reaksiyon çalışmaları sonucunda MA seçiciliğinin \% 95 olarak elde edilmiştir. Katalizör varlığında gerçekleştirilen çalışmalarda sıcaklık artışıla reaksiyonda DA seçiciliğinin arttığı görülmüştür. $363 \mathrm{~K}$ ' de Smopex101 varlığında, DA seçiciliği \% 63' e ve TA seçiciliği $\%$ 14' e yükselmiştir.

Tablo 1. Gliserinin asetik asitle esterleşme reaksiyonu katalizör etkisi, katalizör miktarı; 0,5 g G/AA molar oranı; 6/1, karıştırma hızı; $1000 \mathrm{rpm}$, Süre; 285. dakika (Esterification of glycerol with acetic acid, effect of catalyst, amount of catalyst; $0.5 \mathrm{~g}$, G/AA molar ratio; 6/1, stirring rate; $1000 \mathrm{rpm}$, time; 285 th minute)

\begin{tabular}{|l|c|c|c|c|c|}
\hline Yapılan çalışma & $\begin{array}{l}\text { Reaksiyon } \\
\text { sicaklığı }(\mathrm{K})\end{array}$ & $\begin{array}{l}\text { Gliserin Dönüşümü } \\
(\%)\end{array}$ & \multicolumn{3}{|l|}{ Ürün Seçicilikleri (\%) } \\
\cline { 3 - 6 } & & MA & DA & TA \\
\hline $\begin{array}{l}\text { Katalizörsüz ortamda gliserinin } \\
\text { asetik asitle esterleşme reaksiyonu }\end{array}$ & 298 & 11 & 90 & 10 & 0 \\
\cline { 2 - 6 } & 363 & 13 & 85 & 12 & 3 \\
\hline $\begin{array}{l}\text { Smopex-101 varlığında gliserinin } \\
\text { asetik asitle esterleşme reaksiyonu }\end{array}$ & 298 & 100 & 95 & 3 & 2 \\
\cline { 2 - 6 } & 363 & 100 & 23 & 63 & 14 \\
\hline
\end{tabular}

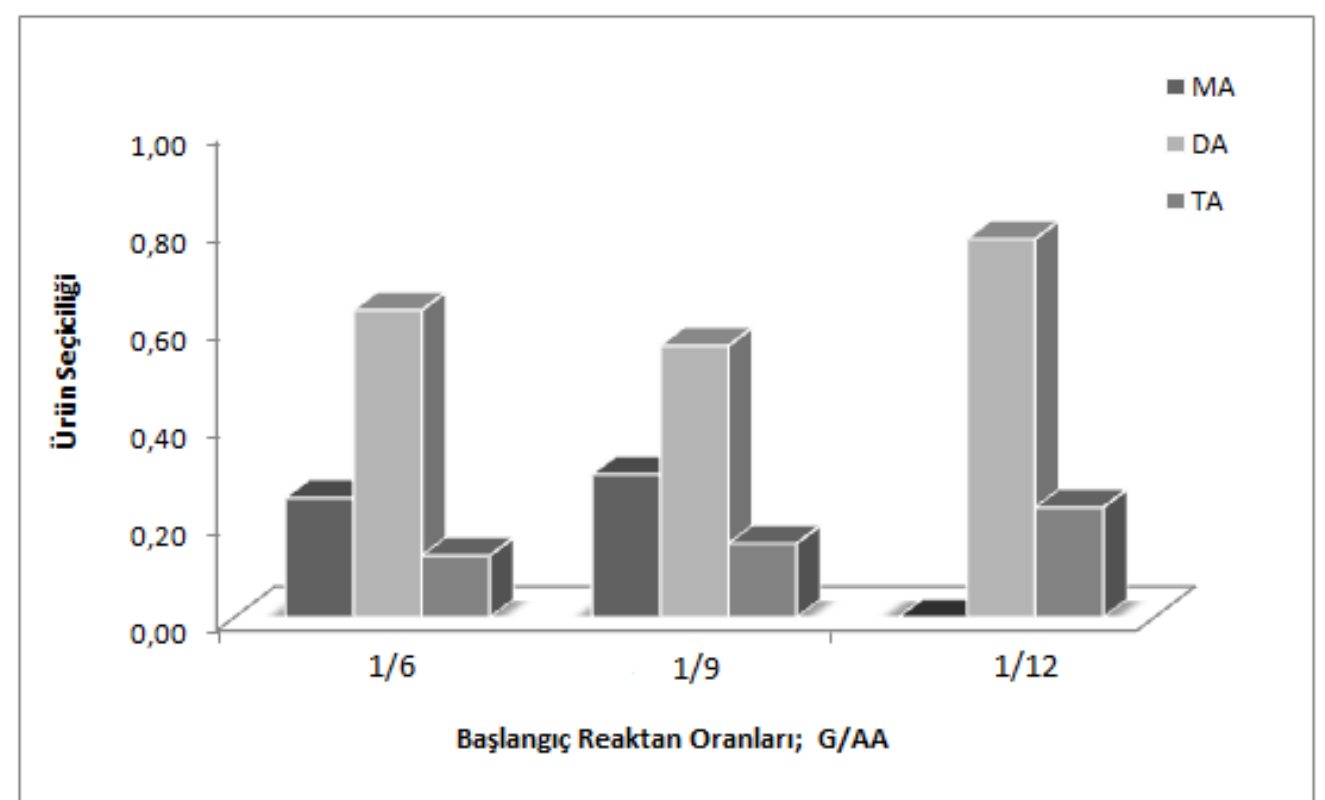

Şekil 4. Başlangıç reaktan oranının ürün seçiciliğine etkisi, T; 363K, katalizör miktarı; 0,5 g, 6/1, karıştırma h1z1; $1000 \mathrm{rpm}$, süre; 285. dakika (Effect of initial molar ratios on the product selectivities (T; 363K, amount of catalyst; $0.5 \mathrm{~g}$, stirring rate; $1000 \mathrm{rpm}$, time; 285th minute) 
Tablo 2. Smopex-101 varlı̆̆ında gerçekleştirilen gliserinin asetik asit ve asetil klorürle reaksiyon çalışmalarına ait veriler, T; $298 \mathrm{~K}$, katalizör miktarı; 0,5 g karıştırma hızı; $1000 \mathrm{rpm}$, süre;1200. dakika (Reaction studies of glycerol with acetic acid and acetyl chlodie in presence of Smopex-101, amount of catalyst; 0.5g, G/AA molar ratio; 6/1, Stirring rate; $1000 \mathrm{rpm}$, time; 285 th minute)

\begin{tabular}{|c|c|c|c|c|}
\hline \multirow[t]{2}{*}{ Yapılan çalışma } & \multirow{2}{*}{$\begin{array}{l}\text { Başlangıç reaktan } \\
\text { molar oranları }\end{array}$} & \multicolumn{3}{|c|}{ Ürün Seçicilikleri (\%) } \\
\hline & & MA & DA & TA \\
\hline Gliserin+ asetik asit esterleşme reaksiyonu & $1 / 6$ & 90 & 6 & 4 \\
\hline $\begin{array}{l}\text { Gliserin +asetik asit+asetil klorür asetilasyon } \\
\text { reaksiyonu }\end{array}$ & $1 / 6 / 1$ & 5 & 35 & 60 \\
\hline
\end{tabular}

\subsection{Başlangıç Reaktan Molar Oranlarının Gliserin Dönüşümüne ve Ürün Seçiciliklerine Etkisi (Effects of Initial Molar Ratio of Reactants on Glycerol Conversion and Selectivities)}

Gliserinin asetik asitle esterleşme reaksiyonu belirtildiği gibi (Şekil 1) üç seri reaksiyondan oluşmaktadır ve ortamdaki asetik asit miktarı ne kadar fazla olursa triasetin seçiciliği o kadar artacaktır. Smopex-101 katalizörü ile $363 \quad \mathrm{~K}$ reaksiyon sıcaklığında G/AA; 1/6, 1/9, 1/12 başlangıç reaktan molar oranlarında reaksiyon çalışmaları gerçekleştirilerek ürün seçicilik dağılımları incelenmiştir. Gerçekleştirilen deneyler sonucunda, üç farklı molar oran için de ilk 25 dakikada \% 100 gliserin dönüşümü sağlanmıştır. Ürün seçiciliklerini incelemek amaciyla reaksiyonlara devam edilmiş ve 285 dakika sonunda sırasıyla DA ve TA seçicilikleri artarken, MA seçiciliğinin azaldığı görülmüştür (Şekil 4). G/AA; 1/12 başlangıç reaktan oranında gerçekleştirilen reaksiyonda 285 dakika sonunda, reaksiyon ortamında MA tamamen tükenerek maksimum DA (\% 77) seçiciliğine ulaşılmıştır. Reaksiyon çözeltisinde asetik asit miktarının artmasıyla gliserin dönüşüm hızı ile birlikte DA ve TA seçiciliğinin arttığ 1 görülmüştür. Bilindiği üzere tersinir reaksiyonlarda reaktanlardan birinin fazla miktarda kullanımı dengeyi ürünler lehine kaydırmaktadır. Gliserinin asetik asitle esterleşme reaksiyonu aynı zamanda seri reaksiyonlardan oluştuğu için ve her basamakta da asetik asit reaksiyona girdiği için asetik asidin fazla miktarda kullanılması oldukça önemlidir. Literatürde yapılan çalışmalara göre asetik asidin fazla kullanımı reaksiyonu ürünler yönüne ilerleterek gliserinin tamamen harcanmasına ve değerli ürünler DA ve TA seçiciliğinin artmasını sağlamaktadır $[13,19,20]$.

\subsection{Gliserinin Asetil Klorürle Asetilasyon Reaksiyonu (Acetylation of Glycerol with Acetyl Chloride)}

Gliserinin asetil klorürle asetilasyon reaksiyon çalışmaları için, öncelikle gliserin ve asetik asit esterleşme reaksiyonu gerçekleştirilmiş, gliserin dönüşü̈mü \% 100' e ulaş̧ıktan sonra ortama asetil klorür ilave edilerek asetilasyon reaksiyonu gerçekleştirilmiştir. Asetilasyon reaksiyonu esterleşme reaksiyonuna benzer şekilde seri yürüyen bir reaksiyondur. Gliserinin asetik asitle esterleşme reaksiyonun da her bir basamakta oluşan birer mol su (Şekil 1) yerine asetilasyon reaksiyonunda birer mol hidroklorik asit $(\mathrm{HCl})$ oluşmaktadır. Asetil klorürün otoklav reaktörde korozyona sebebiyet vermesinden dolayı, asetilasyon reaksiyon deneyleri cam reaktörde gerçekleştirilmiştir. Oda sıcaklığında gerçekleştirilen gliserin-asetik asit-asetil klorür asetilasyon reaksiyonu ve karşılaştırma yapmak amaciyla aynı şartlarda gerçekleştirilen gliserol- asetik asit esterleşme reaksiyonu deney sonuçları Tablo 2'de özetlenmiştir.

Gliserinin asetil klorürle asetilasyon reaksiyonu ile gliserinin asetik asitle esterleşme reaksiyonu sonuçlarından görüldüğü üzere, yüksek sıcaklık ve katalizör varlığında her iki reaksiyon için de \% 100 gliserol dönüşümleri elde edilirken, TA seçiciliklerinde gözle görülür farklar elde edilmiştir. Oda sicaklığında gerçekleştirilen çalışmalarda esterleşme reaksiyonunda düşük $\mathrm{TA}$ seçiciliği görülürken, asetil klorürle gerçekleștirilen asetilasyon reaksiyonunda yüksek TA $\left(\begin{array}{lll}\% & 60\end{array}\right)$ seçiciliğine ulaşılmıştır. $\mathrm{Bu}$ durum, asetil klorürün TA seçiciliği için olumlu bir asetilasyon ajanı olduğunu göstermektedir. Ayrıca gliserinin asetil klorürle asetilasyon reaksiyonu sonucunda hidroklorik asit (HCI) meydana gelmektedir. Asetilasyon ve esterleşme reaksiyonları asidik ortamda gerçekleşen reaksiyonlardır. Reaksiyonda oluşan $\mathrm{HCl}$ 'nin ortamda homojen katalizör gibi davranarak reaksiyon hızını artırabileceği söylenebilir.

\section{SONUÇLAR (CONCLUSIONS)}

Yapılan çalışma ile biyodizel üretiminde yan ürün olarak meydana gelen gliserinden yakıt başlıca yakıt iyileştirici olarak kullanılan gliserin esterlerinin üretimi amaçlanmıştır. Bu doğrultuda Smopex-101 katalizörü varlığında gerçekleştirilen esterleşme ve asetilasyon reaksiyon çalışmalarında elde edilen önemli sonuçlar aşağıda sıralanmıştır.

Asidik özellik gösteren fiber katalizör Smopex-101 varlı̆̆ında gerçekleştirilen esterleşme reaksiyonlarında oda sıcaklığı dahi çalışılan tüm şartlarda ilk 25 dakikada tam gliserin dönüşümü elde edilmiştir. Smopex-101 katalizörünün Amberlyst türevi katalizörlere alternatif olacağı anlaşılmıştır. 
Oda sıcaklığında gerçekleştirilen esterleşme reaksiyonunda maksimum MA seçiciliği(\%95) elde edilmiştir. Reaksiyon sıcaklığının artışıyla birlikte ardışık yürüyen seri reaksiyonlarda DA ve TA seçiciliğinin arttı̆̆ı gözlenmiştir.

Reaksiyonda kullanılan asetik asit miktarının artmasıyla DA ve TA seçiciliğinin arttığı görülmüştür. G/AA; 1/12 başlangıç reaktan oranında gerçekleştirilen reaksiyonda 285 dakika sonunda maksimum DA (\% 77) seçiciliğine ulaşılmıştır.

Esterleşme reaksiyonlarını takiben oda sıcaklığında gerçekleştirilen asetilasyon reaksiyonu çalışmalarında maksimum TA seçiciliği (\% 60) elde edilmiştir.

Asetilasyon çalışmalarında kullanılan asetil klorürün TA seçiciliğini artırmak için etkili bir asetilasyon ajanı olduğu görülmüştür.

\section{KAYNAKLAR (REFERENCES)}

1. Gonçalves, L.C., Pinto, B.P., Silva, J.C., Mota C.J.A., "Acetylation of glycerol catalyzed by different solid acids" Catalysis Today, Cilt 133, 673-677, 2008.

2. Liao X., Zhu, Y., Wang, S.-G., Li, Y., "Producing triacetylglycerol with glycerol by two steps: Esterification and acetylation" Fuel Processing Technology, Cilt 90, 988-993, 2009.

3. Garcia, E., Laca, M., Perez, E., Garrido, A., Peinado, J., "New Class of Acetal Derived from Glycerin as a Biodiesel Fuel Component" Energy Fuels, Cilt 22, 4274-4280, 2008.

4. Casas, A., Ruiz, J., R., Ramos, M.,J., Perez, A., "Effects of Triacetin on Biodiesel Quality" Energy Fuels, Cilt 24, 4481-4489, 2010.

5. Sawant, D. P., Vinu, A., Justus, J., Srinivasu, P., Halligudi S.B., "Catalytic performances of silicotungstic acid/zirconia supported SBA-15 in an esterification of benzyl alcohol with acetic acid", Journal of Molecular Catalysis A: Chemical, Cilt 276, 150-157, 2007.

6. Rönnback, R., Salmi, T., Vuori, A., Haario, H., Lehtonen, J., Sundqvist, A., Tirronen, E., "Development of a kinetic model for the esterification of acetic acid with methanol in the presence of a homogeneous acid catalyst", Chemical Engineering Science, Cilt 52, 33693381, 1997.

7. Jermy, B.R., Pandurangan, A., "A highly efficient catalyst for the esterification of acetic acid using $n$-butyl alcohol", Journal of Molecular Catalysis A: Chemical, Cilt 237, 146-154, 2005.

8. Yadav, G., D., Mehta, P., H., "Heterogeneous catalysis in esterification reactions - preparation of phenethyl acetate and cyclohexyl acetate by using a variety of solid acidic catalysts", Ind. Eng. Chem. Res., Cilt 33, 2198-2208, 1994.

9. Corma, A., Garcia, H., Iborra, S., Primo J., "Modified faujasite zeolites as catalysts in organic reactions: Esterification of carboxylic acids in the presence of HY zeolites", Journal of Catalysis, Cilt 120, 78-87, 1989.

10. Pereira,C., S., M., Pinho, S., P., Silva, V., M., T., M., Rodrigues, A., E., "Thermodynamic equilibrium and reaction kinetics for the esterification of lactic acid with ethanol catalyzed by ion-exchange resin", Ind. Eng. Chem. Res., Cilt 47, 1453-1463, 2008.

11. Yu, G., X., Zhou, X., L., Li, C., L., Chen, L., F., Wang, J., A., "Esterification over rare earth oxide and alumina promoted SO42-/ZrO2", Catalysis Today, Cilt 148, 169-173, 2009.

12. Peters, T., A., Benes, N., E., Holmen, A., Keurentjes, J., T., F., "Comparison of commercial solid acid catalysts for the esterification of acetic acid with butanol" , Applied Catalysis A: General, Cilt 297:182, 2006.

13. Ferreira, P., Fonseca, I.M., Ramos, A.M., Vital J., Castanheiro, J.E., "Esterification of glycerol with acetic acid over dodecamolybdophosphoric acid encaged in USY zeolite", Catalysis Communications, Cilt 10, 481-484, 2009.

14. Zhou, L., Nguyen, T.-H., Adesina, A., A., "The acetylation of glycerol over Amberlyst-15: Kinetic and product distribution", Fuel Processing Technology, Cilt 104, 310-318, 2012.

15. Balaraju, M., Nikhitha, P., Jagadeeswaraiah, K., Srilatha, K., Sai Prasad,P.S., Lingaiah N., "Acetylation of glycerol to synthesize bioadditives over niobic acid supported tungstophosphoric acid catalysts", Fuel Processing Technology, Cilt 91, 249-253, 2010.

16. Maki- Arvela, P., Salmi, T., Sundell, M., Ekman, K., Peltonen, R., Lehtonen, J., "Comparison of polyvinylbenzene and polyolefin supported sulphonic acid catalysts in the esterification of acetic acid", Applied Catalysis A: General, Cilt 184, 25-32, 1999.

17. Lilja, J., Aumo, J., Salmi, T., Murzin, D., MakiArvela, P., Sundell, M., Ekman, K., Peltonen, R., Vainio, H., " Kinetics of esterification of propanoic acid with methanol over a fibrous polymer- supported sulphonic acid catalyst", Applied Catalysis A: General, Cilt 228, 253267, 2002.

18. Peters, A.N., Benes, N.E., "Comparison of commercial solid acid catalysts for the esterification of acetic acid with butanol", Applied Catalysis A: General, Cilt 297, 182188, 2006.

19. Khayoon, M., S., Hameed B., H., "Synthesis of Hibrid SBA-15 functionalized with 
molybdophosphoric acid as efficient catalyst for glycerol esterification to fuel additives", Applied Catalysis A: General, Cilt 433-434, 152-161, 2012.
20. Melero, J., A., Grieken, R., Morales, G., Nuno, V., "Friedel Crafts acylation of aromatic compounds over arenesulfonic containing mesostructured SBA-15 materials", Catalysis Communications, Cilt 5, 131-136, 2004. 